\title{
Delayed traumatic intracerebral haemorrhage
}

\author{
GOPAL BARATHAM AND WILLIAM G. DENNYSON
}

\author{
From the Department of Surgical Neurology, University of Edinburgh
}

SUMMARY Twenty-one out of 7,866 head injuries were complicated by the development of delayed $\overrightarrow{\vec{F}}$ intracerebral haematomata. The age distribution of patients with this condition closely resembledo that of patients with subdural haematomata and differed sharply from patients with extraduralo haemorrhage. This finding, combined with the fact that the two conditions often coexisted, suggests $\frac{\overline{\bar{\rho}}}{\vec{\sigma}}$. the possibility of similar aetiological factors operating in their production. The injury producing the $\mathbb{\varrho}$ lesion was often minor and the larger haematomata appeared to be associated with longer 'asymptomatic' intervals. The neurological deterioration was in most instances clearly the result of an increase $\vec{\circ}$ in intracranial pressure. When possible, angiography followed by definitive craniotomy was the $-\rightarrow$ most satisfactory method of management and multiple burr holes even when combined with needling $\vec{\odot}$ of the hemisphere yielded unsatisfactory results. The distribution of lesions tended to confirm their traumatic origin. On no occasion was there a vascular abnormality to account for the haemorrhageand, despite the fact that the ages of most patients were in the seventh and eighth decades, the $\mathcal{c}_{\mathrm{J}}$ incidence of degenerative vascular disease was small. Contusional injury causes a local failure of the ${ }_{0}$ mechanisms that regulate cerebral blood flow. Hypoxia, hypercapnia, and venous congestion pre-8 duce cerebral hyperaemia which encourages gradual haematoma formation particularly at the sit ${ }_{3}^{\infty}$ of injury. This explains not only the situation of the lesions but also the latency between the traungat and their development.

The prognosis in severe head injuries with extensive cerebral contusions, cerebral lacerations, generalized neuronal disruption, or primary lesions of the brain-stem is notoriously bad. Such cases are recognizable by the unrelenting coma which exists from the moment of injury. Therapeutic attention has therefore been directed towards those patients who develop intracranial space-occupying lesions some time after the initial head injury. These tend to be recovering from the coma due to the concussional injury (even if the classical lucid interval is not always present) and to deteriorate secondarily because of a rise in intracranial pressure. The lesion which most commonly produces this picture is haemorrhage into the extradural or subdural space. The majority of patients with a traumatic intracerebral haemorrhage, usually resulting from severe cerebral lacerations, are profoundly unconscious from the time of injury. In a small minority, however, the intracerebral haemorrhage appears to occur some time after the im- pact. The trend in these patients is one recovery, complete or partial, from the co cussional injury, followed by a deterioration in $N$ the level of consciousness or the development of neurological deficits which were initially absent; such patients are clinically indistinguishable from those with extradural and subdural haematomata. Though the incidence of such $\cong$ cases is small, our interest in them is occasioned $\overrightarrow{\overrightarrow{0}}$ by the fact that they are potentially treatable by removal of the compressing haematoma though, because of destruction of cerebral tissue, treatment is less likely to be as effective as in those situations where the compressive lesions are entirely extracerebral.

Bollinger (1891) originally described the con- $\delta$ dition of delayed intracerebral haemorrhage 3 associated with trauma, and proposed the term $ᄋ$ 'traumatische Spät-Apoplexie'. The original $\supset$ description and that of subsequent workers (Michel, 1896; Bailey, 1904; Symonds, 1940; N Grant and Asutin, 1950; McLaurin and McBride, 
1956; Morin and Pitts, 1970) remain unsatisfactory for various reasons which will be elaborated in the discussion. A major weakness has been that the term 'apoplexy' does not constitute a definite pathological entity. This series is, therefore, limited to those cases in which haematomata occurred primarily into the substance of the brain.

\section{METHODS}

Patients were selected from the total admissions to the traumatic wards of the Department of Surgical Neurology between the years 1960-69. All persons who, associated with trauma to the head, suffered a loss of consciousness, a period of amnesia or complained of symptoms referable to the central nervous system were classified as head injuries and were admitted for observation. In all cases it was possible to obtain a reasonably accurate idea of the severity of the trauma and the initial duration of unconsciousness. Consciousness was considered as being regained when it was possible to obtain rational answers to simple questions and all patients who did not achieve this level of lucidity were excluded.

During the 10-year period 7,866 patients with head injuries were admitted to this department. Intracerebral haematomata were diagnosed in 96 either at operation or necropsy, and of these, 21 had, following definite trauma to the head, a transient period of recovery ('the asymptomatic interval') followed by a secondary deterioration. A detailed study of the case records and necropsy reports of these 21 patients was made. Initially an attempt was made to divide our patients into two groups, one with and the other without evidence of cardiovascular disease. In six instances there was no clinical or necropsy evidence of cardiovascular disease and these would conform exactly to Bollinger's criteria for the diagnosis of 'Spät-Apoplexie'. As these six, however, differed in no other way from the remaining 15 it was felt that any distinction between the groups was arbitrary, if not artificial, and the entire 21 patients were analysed as a single group.

\section{RESULTS}

AGE The oldest patient in this series was 83 years old, and though the youngest was 5 years old, the majority of patients were in the seventh decade. The age distribution of all head injuries was compared with that of extradural haemorrhage, subdural haematoma, and delayed traumatic intracerebral haematoma (Fig. 1). It is

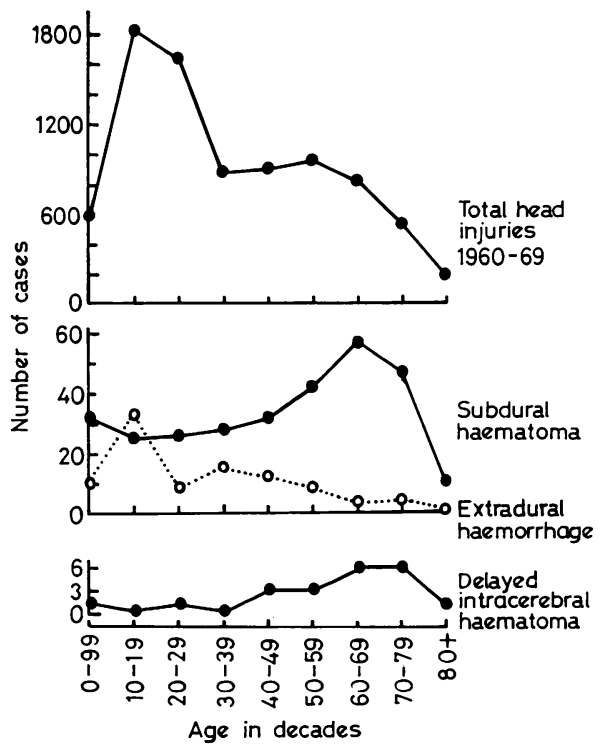

FIG. 1. Age distribution of head injuries and of the various complicating haematomata.

fairly evident that the age incidence of extradural haemorrhage corresponds with the age incidence of all head injuries, the highest frequency being in the second and third decades. The distribution of delayed traumatic intracerebral haemorrhage, however, more closely resembles that of subdural haematoma, the largest incidence being in the seventh and eighth decades. The striking similarity between the age distribution of subdural and delayed intracerebral haematomata, and the sharp distinction between the age incidence of these two conditions and that of extradural haemorrhage suggests the possibility that similar causal mechanisms may operate in the production of subdural and delayed intracerebral haematoma.

NATURE OF HEAD INJURY The severity of the initial head injury was assessed both in terms of the duration of coma as well as from the point of view of the trauma producing it. Those patients with an initial period of unconsciousness of under five minutes were classified as minor; those unconscious for up to an hour were classified as moderate; those unconscious for over an hour were considered major. Twelve cases were considered to have had minor head 
injuries, and nine moderate ones. In no instance did the initial coma last for over an hour. Though it is impossible to assess the severity of impact with scientific accuracy, it was felt that some rough clinical impression of this was possible. The impact was classified as being mild, moderate, or severe, depending on the circumstances of the accident. For example, falls from the same level were classed as mild, collisions between pedestrians and motor vehicles were deemed severe, and those between pedestrians and pedal cycles were considered moderate. In only three instances were the impacts considered severe; eight were moderate, and 10 mild. These findings substantiate the view that intracerebral haematomata can occur after a minor head injury caused by a trivial accident.

'ASYMPTOMATIC' INTERVAL This was the interval between the initial recovery of consciousness and the secondary deterioration. The shortest was one and a half hours and the longest 19 days (Table 1). When this period was under 24 hours most patients were not strictly asymptomatic and

TABLE 1

DURATION OF 'ASYMPTOMATIC' INTERVAL

\begin{tabular}{lc}
\hline 'Asymptomatic' interval & $\begin{array}{c}\text { Patients } \\
\text { (no.) }\end{array}$ \\
\hline $1-5 \mathrm{hr}$ & 2 \\
$6-11 \mathrm{hr}$ & 3 \\
$12-24 \mathrm{hr}$ & 5 \\
$1-2$ days & 4 \\
$3-7$ days & 4 \\
$8-14$ days & 2 \\
Over 14 days & 1 \\
\hline
\end{tabular}

had minor headache as a sequel to concussion for which they were still under observation. They were all, however, well enough to answer simple questions, had no neurological deficits, and did not have headache of any severity. An attempt was made to correlate the duration of the 'asymptomatic' interval with the size of the haematoma as measured at necropsy. Necropsy material was used, as estimates of haematoma size at operation are notoriously inaccurate (Table 2). It seemed possible that the more
TABLE 2

'ASYMPTOMATIC' INTERVAL AND HAEMATOMA SIZE

\begin{tabular}{lccc}
\hline $\begin{array}{l}\text { Duration of } \\
\text { asymptomatic' interval }\end{array}$ & \multicolumn{3}{c}{ Number of patients } \\
\cline { 2 - 4 } & $\begin{array}{c}\text { Haematoma } \\
\text { under } 3 \mathrm{~cm}\end{array}$ & $\begin{array}{c}\text { Haematoma } \\
4-6 \mathrm{~cm}\end{array}$ & $\begin{array}{c}\text { Haematoma } 7 \mathrm{~cm} \\
\text { over }\end{array}$ \\
\hline
\end{tabular}

\begin{tabular}{ccll}
\hline $1-5 \mathrm{hr}$ & 1 & 0 & 0 \\
$6-11 \mathrm{hr}$ & 0 & 0 & 1 \\
$12-24 \mathrm{hr}$ & 2 & 2 & 1 \\
$1-2$ days & 0 & 1 & 3 \\
$3-7$ days & 0 & 0 & 1 \\
$8-14$ days & 1 & 1 & 0 \\
Over 14 days & 0 & 1 & 0 \\
\hline
\end{tabular}

slowly developing haematomata would allow $\stackrel{\mathbb{Q}}{\varrho}$ compensatory mechanisms to occur within the intracranial cavity and would eventually reach a $\overrightarrow{0}$ greater size than those in which the bleeding was more rapid. This group would therefore be associated with a longer 'asymptomatic' interval. The wide dispersion of the figures is probably a reflection of the multiplicity of factors which operate in determining the final size of the haematoma cavity. The haematomata were divided into two groups according to their siz the smaller having diameters of $4 \mathrm{~cm}$ or less ang the larger with diameters greater than this. appeared (Table 3 ) that the larger lesions were associated with an 'asymptomatic' interval 웜요 24 hours or more.

TABLE 3

'ASYMPTOMATIC' INTERVAL AND HAEMATOMA SIZE

\begin{tabular}{lcc}
\hline 'Asymptomatic' interval & \multicolumn{2}{c}{ Number of patients } \\
\cline { 2 - 3 } & $\begin{array}{c}\text { Haematoma } \\
\text { under } 4 \mathrm{~cm}\end{array}$ & $\begin{array}{c}\text { Haematoma } \\
\text { over } 4 \mathrm{~cm}\end{array}$ \\
\hline $\begin{array}{l}\text { Under } 24 \mathrm{hr} \\
\text { Over } 24 \mathrm{hr}\end{array}$ & 3 & 1 \\
\hline & 1 & 10 \\
\hline
\end{tabular}

NEUROLOGICAL DETERIORATION Depression in the level of consciousness was the commonest manifestation of neurological deterioration and 9 occurred in 13 patients. On six occasions this $\frac{7}{0}$ was sufficiently rapid to produce deep coma before operative intervention. Headache of in- $N$ 
creasing severity occurred in four patients but never as a solitary symptom; in three it was associated with a reduction in the level of consciousness and in the fourth with an oculomotor palsy. Only two patients developed a hemiparesis and in both it was of fairly sudden onset. In no instance did seizures occur. With respect to the rarity of pareses and the absence of seizures, the findings of the present series differ from that of McLaurin and McBride (1956).

Deepening coma, increasing headache, and oculomotor paresis are indicative of a rising intracranial pressure. In all but one instance-a patient with a cerebellar haematoma-the rise in pressure was supratentorial. The natural sequence of events with an enlarging supratentorial mass is uncal herniation and, if this is not expeditiously and adequately relieved, death. Eight patients were found at necropsy to have asymmetrical uncal and transfalcine herniation. In five of these an antemortem diagnosis of intracerebral haematoma was made and the persistence of herniation at necropsy implies that treatment was either ineffective or tardy. An attempt was made to discover possible causes for the development of haematomata or the expansion of existing lesions. In particular, attention was directed towards the possibility of hypoxic episodes producing cerebral hyperaemia and enhancing haematoma formation. In four instances cerebral hypoxia with or without an element of venous engorgement may have occurred. In two this was the result of myocardial insufficiency, one patient having an anginal attack immediately preceding the onset of coma and the other providing at necropsy evidence of recent myocardial infarction. On one occasion necropsy revealed chronic bronchitis, emphysema, and right ventricular hypertrophy and, though there was no clinical description of a hypoxic episode, both hypoxia and venous engorgement were both chronically present. A fourth patient had at necropsy diffuse anoxic changes of the cerebral cortex, kidney, and myocardium though no cause for this could be found. In a further two patients it was possible to suggest a cause of haematoma formation. The first had a thrombosis of the left lateral sinus underlying a fracture of the temporal bone. Deterioration occurred about 36 hours after the head injury, and it is probable that obstruction of the sinus predisposed towards haematoma formation by causing intracranial venous congestion. In the second patient (described in detail later), evacuation of a tense subdural haematoma may have provoked enlargement of an intracerebral one. In 15 of the 21 patients, however, it was not possible to suggest a cause for delayed haematoma formation. This, however, does not exclude the possibility of transient and undetected episodes of hypoxia acting as a precipitating factor.

RADIOLOGICAL STUDIES Ten patients had skull fractures and six of these subsequently developed haematomata in relation to the fracture sites. In five of these there was evidence of cerebral contusion or laceration underlying the fracture site implicating the direct or 'coup' mechanism of injury. Two patients with posteriorly placed fractures developed haematomata and contusions of the frontal lobes. These were clearly examples of the 'contre-coup' type of injury. Eight patients were investigated by carotid angiography. In four the haematomata were satisfactorily located. In three instances angiography revealed subdural collections which were assumed to be the cause of the vascular displacements. There is no doubt that the composite nature of the lesion interfered with the accuracy of angiographic diagnosis. In a single case the intracranial pressure was high enough to prevent filling of the internal carotid artery beyond the level of the siphon. Ventriculography was undertaken only once, in a patient with an unsuspected cerebellar haematoma.

Though angiography provided the diagnosis in only half the patients thus investigated, because of the anterior location of most of the lesions (Fig. 2), it would appear to be the most suitable diagnostic procedure. It has been suggested (McLaurin and McBride, 1956) that ventriculography is the investigation of choice as it can be combined with exploratory burr holes. It is not possible to say on the experience of the present series whether or not this is so. It is likely, however, that in the presence of cerebral oedema ventricular cannulation may be difficult and ventricular filling insufficient to be of diagnostic value.

Echoencephalography is attractive because it is swift, innocuous, and can be easily repeated. A 
shift of the midline was demonstrated in 10 patients with supratentorial lesions, while in the remaining 10 the echo was midline or the examination inconclusive. A midline echo does not, therefore, exclude the presence of a haematoma and must be interpreted in conjunction with other available data.

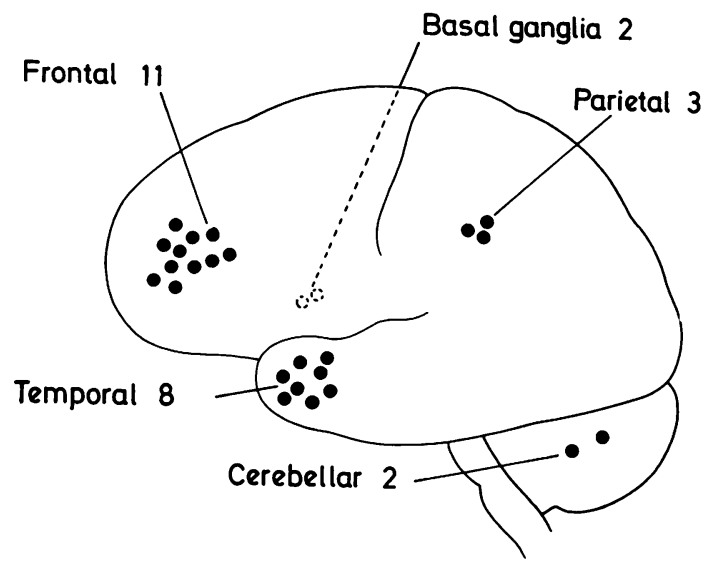

FIG. 2. Distribution of haematomata. Five occurred at multiple sites.

It is not possible to suggest an ideal diagnostic procedure for the location of traumatic intracerebral haematomas for this will depend on several factors and must eventually be determined by the urgency of the clinical situation. It does appear, however, that carotid angiography is most likely to provide information about the site of the lesion though the presence of a surface haematoma may confuse the diagnosis.

OPERATIVE MANAGEMENT All 21 patients had some form of operative treatment. In seven this was limited to burr holes and in only two of these was an operative diagnosis made. Fourteen underwent either a craniotomy or craniectomy and the diagnosis was made or confirmed at operation on nine occasions. In four of these a preoperative angiogram had established the presence of an intracerebral mass and the craniotomy was entirely elective. The figures, however, imply that burr holes, even when multiple and combined with needling of the hemisphere, may provide inadequate exposure for an operative diagnosis. Subdural collections of one kind or another were found on $15^{\Phi}$ occasions and possibly confused the picture. On eight occasions, in patients with acute subdural collections, the coexisting intracerebral lesion was overlooked, the neurological deterioration? being attributed entirely to the presence of the surface haematoma. Eleven patients were found $\stackrel{\vec{m}}{\overrightarrow{7}}$ to have a thin film of subdural blood, three had. massive solid haematomas, and in one the collec- $\overrightarrow{\overline{\mathrm{s}}}$ tion was of the chronic fluid variety. This patiento illustrates several points and will be described in detail.

\section{CASE REPORT}

F.B., a 79 year old man, was admitted to our wards $\overrightarrow{0}$ on 17 July 1969. Twelve days previously he had fallen while drunk and was admitted to a general $\vec{\sigma}$ surgical unit. He rapidly regained consciousness and after being observed for three days was discharged home free of any neurological deficits. He remained $\omega$ well for 11 days and then was noticed to be slightly or confused. On the following day he became pri-s gressively more drowsy and was admitted to the neurosurgical unit. At the time of admission $\mathrm{he}^{\circ}$ would not obey simple commands but responded painful stimuli by withdrawal movements whiç were less vigorous on the left side. Both plantgr? responses were extensor. Echoencephalograp showed a right-to-left shift of $1 \mathrm{~cm}$. Biparietal at bifrontal burr holes were immediately made. On t right side there was a large fluid subdural collection? of dark altered blood which was under considerable tension. No abnormality was noted on the left side. The subdural haematoma was evacuated and the subdural space irrigated with saline. Though the gyri were shrunken, indicating an absence of oedema $\mathbb{D}$ and some degree of atrophy, the brain expanded $\vec{F}$ rapidly. A silver clip was attached to the cortex so as $\frac{0}{3}$ to provide a radiological guide to the size of the subdural space in the event of reaccumulation.

After surgery his level of consciousness improved and he was obeying simple commands. Four hours later, however, he rapidly lapsed into coma, responding to painful stimuli only by decerebrate posturing. Radiographs of the skull showed the silver clip abutting on the inner table of the skull, indicating that the subdural haematoma had not reaccumulated and this was confirmed by reopening the burr holes. Needling the parietal lobe produced darkish blood, $\frac{D}{0}$ followed by fresh blood mixed with CSF. It was felt that he had suffered a massive periventricular $N$ haemorrhage and no further treatment was attemp- 
ted. He died shortly after surgery and necropsy revealed a massive haemorrhage in the right parietal lobe with rupture into the lateral ventricle.

The subdural fluid evacuated initially was undoubtedly the result of the head injury 12 days previously. It is possible that sudden removal of the surface collection provoked expansion of the deep haematoma, particularly as the cavity was found at operation to contain both altered and fresh blood. The finding of a substantial surface haematoma and the absence of brain swelling undoubtedly led to the deeper lesion being overlooked initially. Whether or not an episode of hypoxia could have occurred during the period of coma and whether the hyperaemia associated with this precipitated further haemorrhage must remain a matter for speculation.

PATHOLOGICAL FINDINGS Fifteen of the 21 patients died and were subjected to necropsy examination. In every case an assessment was made of the severity and distribution of atheromatous disease, particular attention being paid to its occurrence in the coronary and cerebral vessels. A special search was made for aneurysms and arteriovenous malformations which could account for the haemorrhage. In only one instance was an unruptured aneurysm of the anterior communicating artery discovered and this was not thought to be relevant to the haematoma located in the parietal lobe. All haematomata were substantial-that is, none were 'slit' haemorrhages and their size was expressed in respect of their greatest diameter. This ranged from $2.5 \mathrm{~cm}$ to $15 \mathrm{~cm}$ with a mean of $6 \mathrm{~cm}$ and generally, therefore, formed significant space-occupying lesions. An obvious feature of the distribution of lesions (Fig. 2) is the frequency with which the frontal and temporal lobes were involved. This finding is in keeping with that of earlier workers (Courville and Blomquist, 1940; Browder and Turney, 1942; Courville, 1962). A noticeable difference between the present and previous reports is the absence of haematomata in the occipital region and the frequency of multiple lesions which were found on five occasions (Table 4). Though multiple lesions have been reported (De Jong, 1942) they do not appear to be a common finding (Bollinger, 1891; McLaurin and McBride, 1956; Morin and Pitts, 1970). The infrequency of multiple haematomata in earlier series is surprising, as more than one area of the brain is damaged at the moment of impact and similar pathological processes presumably operate at all of these sites, even if Bollinger's original supposition of trauma producing a diffuse cerebral softening is not acceptable to-day.

TABLE 4

SITUATION OF MULTIPLE LESIONS

\begin{tabular}{lc}
\hline Sites & $\begin{array}{c}\text { Patients } \\
\text { (no.) }\end{array}$ \\
\hline R. frontal + R. cerebellar & 1 \\
R. frontal + R. temporal & 2 \\
R. temporal + L. temporal & 1 \\
R. frontal + basal ganglia & 1 \\
\hline Total & 5 \\
\hline
\end{tabular}

Two patients had haematomata in the basal ganglia and this finding is generally accepted as proof of their hypertensive aetiology (Johansson, 1961). Courville (1962) has, however, described symmetrical basal gangliar haemorrhages and suggested a traumatic aetiology because of the bilaterality of the lesions. Although both patients with basal gangliar haemorrhage were elderly, in neither was there any clinical or necropsy evidence of either atheromatous or hypertensive disease. In both, the history of trauma was sufficiently definite to preclude the possibility of a spontaneous hypertensive haemorrhage resulting in incidental trauma, one patient being struck by a girder while at work and the other run down by a car while crossing a street. Further, in neither did a period of hypertension, as could possibly result from raised intracranial pressure, occur before the neurological deterioration. A feature of interest is that one of the gangliar lesions was associated with an ipsilateral frontal haematoma and that both conditions appeared to be of the same age at necropsy. The pathological mechanism producing these lesions, however, remains obscure. The two cerebellar haematomata are also of interest. The first resulted from an occipital blow which produced a fracture of the occiput and an underlying laceration of the cerebellum. The second was found in association with a frontal haematoma caused by a blow high on the forehead. 
The association between the haematomata and cerebral contusion or lacerations was studied. On 10 occasions haematomata were found in association with contusions or lacerations. In only two of these was there a possible cause for the neurological deterioration. Of five patients without obvious superficial focal brain injury it was possible to suggest a cause for haematoma formation on three occasions. This finding suggests that under certain conditions small traumatic haemorrhages in the white matter can increase sufficiently to become of clinical significance. The suggestion that haematomata not associated with contusional injury have a better prognosis than those with such injury (McLaurin and McBride, 1956) could not be substantiated as only necropsy material was used in separating patients into two groups. Although the tendency to contusional injury increases with ageing and degenerative vascular disease, in only eight patients was there evidence of degenerative changes affecting both the coronary and cerebral vasculature. Minckler (1971) has suggested the possibility of sudden increase of size of contusional haemorrhages in alcoholics. On two occasions this may have been the case. In the first, a known alcoholic, precipitous deterioration occurred 24 hours after injury. In the second, the deterioration, though equally sudden, occurred 12 hours after a fall and was caused by a haematoma $9 \mathrm{~cm}$ in diameter. This woman, though not an overt alcoholic, was found at necropsy to have evidence of Wernike's encephalopathy.

\section{DISCUSSION}

Apoplexy is a term of dubious validity as it does not denote a specific pathological entity. By common consent it has come to include all conditions caused by '. . . acute vascular lesions of the brain' (Dorland, 1965). Unfortunately, several different diseases fall into this category and the tendency to group them all as a single entity has served only to confuse accurate diagnosis. The first of Bollinger's four cases appeared to have had a subdural haematoma and the third secondary brain-stem haemorrhages resulting from raised intracranial pressure due to an internal hydrocephalus. Undoubtedly, the pathology of the various forms of intracranial haemorrhage was not well elucidated at the end of the last century and it is, therefore, injudicious to attempt to adhere rigidly to the criteria proposed by Bollinger as Morin and Pitts (1970) have done.

A further problem arises when the interval between the trauma and the 'apoplectiform episode' is prolonged. Unless a definite pathological sequence of events can be established, the relevance of the trauma must remain uncertain. In fact the trauma, particularly when minor, may have been purely fortuitous and remembered only because of the development of symptoms referable to the head. Further, the relatively high incidence of 'Spät-Apoplexie' in the young may merely reflect the fact that this group is more prone to injury than the more senior members of the community.

Two forms of delayed intracerebral haemorrhage have been described after trauma. The first occurs within the substance of the brain, and the second primarily within the ventricular system. It is well established that blood staining of the cerebrospinal fluid occurs after head injuries (Russell, 1932) and that this can resulf even after minor trauma (Grahmann and Schmidt, 1964), though it is difficult to relate traumatic subarachnoid haemorrhage to thes delayed intraventricular haemorrhage whicho occurs in association with trauma. Further, it is not impossible that different pathological mech anisms may operate in producing ventricular, as opposed to intracerebral, haemorrhage. This is particularly so as trauma is known to precipitate haemorrhage from arteriovenous malformations (Ameli, 1968). Such lesions produce haemorrhage within the CSF pathways and may be difficult to demonstrate at necropsy, especially when they are small. Because of these considerations this study has been limited to patients with haemorrhage into the substance of the brain of indubitable traumatic origin.

The mechanism producing cerebral contusions after blunt head injuries has been well studied (Gurdjian, Lissner, Hodgson, and Patrick, 1966), and Courville (1962) has divided the traumatic haematomata so produced into those associated with superficial cerebral contusions and those which occurred independently in the white matter. Though the work of Courville and Gurdjian explains the occurrence and situation 
of the haematoma, it does not explain the latency between the injury and the development of symptoms. Bollinger's original submission that trauma produced progressive cerebral softening and that haemorrhage occurred when this involved the wall of a blood vessel is difficult to prove. The vasoparalytic theory of Evans and Scheinker (1946) suffers from the same weakness though both would satisfactorily explain the period of latency.

It is well recognized that both hypoxia and hypercapnia can increase cerebral blood flow. Cairns (1939) showed that the brain swelling which occurred with carbon dioxide retention and the trauma of retraction was caused by cerebral vasodilatation. More recently, animal experiments have demonstrated that trauma produces an increase in regional cerebral blood flow, not only in the traumatized area but also in the brain surrounding it, and that the hyperaemia in the surrounding brain persists for an indefinite period after the trauma (Brock, 1968). It has further been suggested (Langfitt, Kumar, and Millar, 1971) that the increased arterial pressure consequent upon hypoxia can, because of a local loss of autoregulation, be transmitted to the veins, thus facilitating diapedesis. The demonstration (Langfitt, Weinstein, and Kassell, 1966) that the vasodilatation occasioned by carbon dioxide retention may persist even after resumption of normal respiration is also relevant. A combination of factors, therefore, operates in the production of the delayed variety of traumatic intracerebral haemorrhage. Focal trauma produces increased flow within and around traumatized brain. Hypoxia, carbon dioxide retention, and any cause for elevation of venous pressure will increase this tendency, thus producing ideal conditions for the gradual development of an intracerebral haematoma. It is now possible to formulate a sequence of events suggesting aetiological mechanisms and offering a correlation between pathological findings and clinical manifestations.

Trauma of a trivial nature can produce marked displacements in the atrophic brains of elderly persons. These result in contusions or lacerations of usually the frontal and temporal regions but whose exact site will depend on the site of the impact. A similar mechanism can produce subdural bleeding and, through dis- ruption of bridging corticodural veins, is an added factor in subdural haemorrhage (Krauland, Mallach, Mussoni, and Spitz (1962), and this probably explains the similarity of age distribution and the coexistence of the two conditions. Injury, whether a contusion or a laceration, produces the prerequisites for haemorrhage within the brain substance. The likelihood of this is increased by conditions of hypoxia, hypercapnia, or venous congestion. The bleeding is rarely brisk, differing in this respect from that of middle meningeal haemorrhage, and probably consists of oozing from venules. The larger haematoma cavities appear to take a greater time to develop and are associated with a longer 'asymptomatic interval'. Eventually the haematoma produces a rise in intracranial pressure and may rupture into the subdural space or into the ventricular system. It is possible that decompression of a surface collection may provoke further haemorrhage into an existing deeper haematoma, though the view of Lafforgue (1904) that trauma produced bleeding into an already existing spontaneous haematoma cavity is difficult to prove. Though the operative results in this series are not encouraging, the slow development and the absence of neurological deficits before those from raised intracranial pressure supervene, imply that the condition is potentially treatable. Failure to recognize the syndrome undoubtedly accounts for the high mortality in this series as an antemortem diagnosis was made on only nine occasions.

Clinicians have for some time recognized that traumatic haemorrhage into the brain substance can occur some time after a head injury and Lin, Cook, and Browder (1958) have stressed the difficulties involved in distinguishing clinically between the deep haematoma and the more commonly occurring superficial variety. Neither the incidence of this syndrome nor the relationship between its pathogenesis and its clinical presentation appears to have been adequately explored.

It is a pleasure to acknowledge our gratitude to Professor F. John Gillingham and Mr. John Shaw for their valuable guidance, to Dr. K. Hermann for her assistance and advice with the German literature, to Mr. Phillip Harris and Mr. Edward Hitchcock for permission to use their cases, and to Miss V. PictonPhillipps who assisted with processing the data. 


\section{REFERENCES}

Ameli, N. O. (1968). Brain angiomata and intracerebral haematoma. Progress in Brain Research, 30, 427-431.

Bailey, P. (1904). Traumatic apoplexy. Medical Record, 66, 528-529.

Bollinger, O. (1891). Ueber traumatische Spät-Apoplexie. Ein Beitrag zur Lehre von der Hirnerschütterung. Internationale Beiträge zur Wissenschaftlichen Medicin. Festschrift, Rudolf Virchow. Berlin A. Hirschwald. 2, 457-470.

Brock, M. (1968). Experimental 'luxury perfusion' in the cerebral cortex of the cat. Progress in Brain Research, 30, 125.

Browder, J., and Turney, M. F. (1942). Intracerebral hemorrhage of traumatic origin: its surgical treatment. New York State Journal of Medicine, 42, 2230-2235.

Cairns, H. (1939). Raised intracranial pressure: hydrocephalic and vascular factors. British Journal of Surgery, 27, 275-294.

Courville, C. B., and Blomquist, O. A. (1940). Traumatic intracerebral hemorrhage, with particular reference to its pathogenesis and its relation to 'delayed traumatic apoplexy'. Archives of Surgery, 41, 1-28.

Courville, C. B. (1962). Traumatic intracerebral hemorrhages, with special reference to the mechanics of their production. Bulletin of the Los Angeles Neurological Society, 27, 22-38.

Dorland, W. A. N. (1965). Dorland's Illustrated Medical Dictionary. 24th edn., p. 120. Saunders: Philadelphia.

Evans, J. P., and Scheinker, I. M. (1946). Histologic studies of the brain following head trauma. II. Post-traumatic petechial and massive intracerebral hemorrhage. Journal of Neurosurgery, 3, 101-113.

Grahmann, H., and Schmidt, H. (1964). Liquoruntersuchungen bei frischen gedeckten traumatischen Hirnschäden. Zentrablatt für Neurochirurgie, 24, 282-289.

Grant, F. C., and Austin, G. M. (1950). The surgical treatment of spontaneous and traumatic intracerebral hemorrhage. American Journal of Medical Science, 219, 237-241. Gurdjian, E. S., Lissner, H. R., Hodgson, V. R., and Patrick, L. M. (1966). Mechanism of head injury. Clinical Neurosurgery, 12, 112-128.
Johansson, S. H. (1961). Hypertensive and normotensive

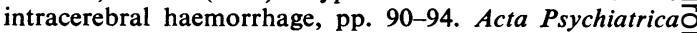
et Neurologica Scandinavica, 36, Suppl. 150.

Krauland, W., Mallach, H. J., Missoni, L., and Spitz, W. U.'ं (1962). Subdurale Blutungen aus isolierten Verletzungen $\subseteq$ von Schlagadern on der Hirnoberfläche dur Stumpfe Gewalt. Virchows Archiv für pathologische Anatomie und Physiologie, 336, 87-98.

Lafforgue, E. (1904). Hemorragies intra-craniennes trauma- $T$ tiques évoluant en deux temps. Bulletin Médical (Paris), 18, 875-878.

Langfitt, T. W., Kumar, V. S., and Miller, J. D. (1971). Cerebral oedema caused by anoxia and changes in intracranial vascular pressures. In Brain and Blood Flow. Pro-ceedings of the 4th International Symposium on the Regulation of Cerebral Blood Flow, pp. 386-392. Edited by R. W. R. Russell. Pitman Medical: London.

Langfitt, T. W., Weinstein, J. D., and Kassell, N. F. (1966). Vascular factors in head injury. Contribution to brain- $\overline{\bar{c}}$ swelling and intracranial hypertension, pp. 172-194. Edited by W. F. Caveness, and E. A. Walker. Head Injury. $₫$ Conference Proceedings. Lippincott: Philadelphia.

Lin, T. H., Cook, A. W., and Browder, E. J. (1958). Intracranial hemorrhage of traumatic origin. Medical Clinics of $\vec{\circ}$ North America, 42, 603-610.

McLaurin, R. L., and McBride, B. H. (1956). Traumatic $\vec{\omega}$ intracerebral hematoma. Review of 16 surgically treated $D$ cases. Annals of Surgery, 143, 294-305.

Michel, E. (1896). Ein Beitrag zur Frage von der sogenannten traumatischen Spätapoplexie. Wiener klinische Wochenscrift, 9, 789-793.

Minckler, J. (Editor) (1971). Pathology of the Nervous System or p. 1729. Vol. 2. McGraw-Hill: New York.

Morin, M. A., and Pitts, F. W. (1970). Delayed apople following head injury ("traumatische Spät-Apoplexiec. Journal of Neurosurgery, 33, 542-547.

Russell, W. R. (1932). Discussion on the diagnosis afo treatment of acute head injuries. Proceedings of the Royal Society of Medicine, 25, 751-757.

Symonds, C. P. (1940). Delayed traumatic intracereb영응 haemorrhage. British Medical Journal, 1, 1048-1051. 